\title{
Variable-Load Heat Pumps: Impact of the Design and Control Parameters on the Actual Operation Conditions
}

\author{
Alice Mugnini $^{1 *}$, Gianluca Coccia ${ }^{1}$, Fabio Polonara ${ }^{1,2}$, Alessia Arteconi ${ }^{1,3}$ \\ ${ }^{1}$ Dipartimento di Ingegneria Industriale e Scienze Matematiche (DIISM), Università Politecnica delle Marche, Via Brecce \\ Bianche 1, Ancona 60131, Italy \\ ${ }^{2}$ Consiglio Nazionale delle Ricerche (CNR): Construction Technologies Institute, Viale Lombardia 49, San Giuliano Milanese \\ 20098, Italy \\ ${ }^{3}$ Department of Mechanical Engineering, KU Leuven, Leuven B-3000, Belgium
}

Corresponding Author Email: a.mugnini@univpm.it

https://doi.org/10.18280/ti-ijes.652-434

Received: 12 March 2021

Accepted: 28 May 2021

\section{Keywords:}

variable-load heat pump, air-to-water heat pump, control strategy, design parameters, actual energy performance

\begin{abstract}
Nowadays heat pumps (HPs) represent the main alternative to traditional heating systems for the transition to nearly zero-energy buildings. Though HPs are a well-known technology, the estimation of their actual energy performance is still under discussion. Indeed, the proper choice of the HP design parameters (e.g. size, rated supply temperature) and the adopted control strategy can assume a paramount role to cover the mismatch between declared and actual performance of the system. Objective of this work is to analyze this mutual dependence in an operating system to provide guidelines for the design of a residential heating system with a HP. Through a dynamic energy simulation tool, a variableload air-to-water HP is used to cover the thermal demand of a residential building. The effect of the reciprocal influence of different design choices (e.g. rated heating capacity or design supply temperature) and control strategies (e.g. climatic regulation) is analyzed by simulating different scenarios. To complete the evaluation, the impact of a thermal energy storage is also assessed. The study allows to identify guidelines for the design of different system configurations and results seem to confirm the impact of the investigated parameters on the seasonal performance of the system.
\end{abstract}

\section{INTRODUCTION}

According to the International Energy Agency (IEA), nearly 20 million households purchased heat pumps (HPs) in 2019, making them the most common technology in newly built houses in many countries [1]. As highlighted by Fischer and Madani [2], the interest in promoting the diffusion of HPs is motivated by several factors. First, the growing progress in the development of this technology. About this, the IEA in a recent report estimated that the typical seasonal performance factor of HPs has increased steadily since 2010 to reach today a Coefficient of Performance (COP) nearly 4 for most space heating applications. A second advantage concerns the fact that HPs allow the exploitation of renewable electricity generation systems, which are increasingly widespread. Furthermore, thanks to the fact that HPs establish a direct link between the thermal and electrical demand of the building, they allow to use the different thermal inertia sources contained in the building (i.e. thermal mass of the envelope or dedicated devices as thermal energy storages, TESs) to implement strategies aimed at decoupling the thermal power generation from the demand. This last aspect represents a third advantage of fundamental importance as it would allow to cope with the intermittent and non-programmable nature of the most widespread renewable energy sources (photovoltaic and wind).

It is therefore clear that HPs represent the main alternative to traditional heating systems for the building transition to the
nZEBs (nearly Zero-Energy Buildings). For this reason, in recent years, the use of heat pumps in buildings is a muchstudied topic both in scientific literature and in regulatory practice. One of the aspects that attracts most of the attention concerns the estimation of their actual energy performance.

For the energy efficiency evaluation, different standards address the issue of estimating the performance dependence on the outdoor temperature and on the building thermal load. For instance, the Italian standard UNI TS 11300-4 [3], which is based on the European standard EN 14825 [4], proposes to use the "bin method" to dynamically evaluate the HP performance, starting from the data provided by manufacturers. However, in many cases, the actual seasonal coefficient of performance (SCOP) is different from the one declared in manufacturer's data or calculated with the standards [5]. This is due to the fact that the actual performance of the heat pump is very dependent on the operating conditions of the system (i.e. external temperature and supply water temperature). Furthermore, when variable load heat pumps are considered, the performance is also influenced by the load modulation. It is therefore clear that the proper choice of the HP design parameters (e.g. size, rated supply temperature) in addition with the adopted control strategy (e.g. climatic regulation) have a paramount role on the actual performance of the system.

There are many works in literature that address the problem of choosing the optimal size of the components of a heating system equipped with a heat pump. For instance, Dongellini et al. [6] evaluated the influence of sizing and of control rules on 
the energy saving potential of a hybrid heating system (i.e. heat pump in combination with an electric heater or a condensing gas boiler) in a residential building. With a heat pump sized to cover up to $74 \%$ of the design thermal load, they evaluated primary energy savings between $6 \%$ and $22 \%$ with respect to the reference monovalent configurations (based on an air-to-water heat pump and a condensing gas boiler, respectively). Another interesting work was proposed by Lin et al. [7]. They investigated the optimal combination of supply air temperature, load side, source side supply and return water temperature to maximize the energy and exergy performance of a ground source heat pump system serving an office building in Wuhan (China). They observed that the variable air and water flow volume system under design operation allows to improve the COP of $70.5 \%$ in summertime and of $138.4 \%$ in wintertime. Also, Blackman et al. [8] proposed an evaluation of a heat pump coupled with a residential building. In particular, they modelled a bivalent heating system consisting of a sorption heat pump and a condensing boiler. In this study, the authors varied from $0 \%$ to $100 \%$ the sorption heat pump design heating capacity as a fraction of the bivalent system total heating capacity. Their results indicated that the design heating capacity ratio of the sorption module that leads to the shortest payback period is between 0.34 and 0.42 . Moreover, Ayele et al. [9] proposed an integrated optimization algorithm for the sizing and for the optimal placement of heat pumps. Considering also the availability of different energy sources (e.g. solar photovoltaic, wind turbines and imports from the neighborhood grids), they individuated an optimal configuration in which potential savings up to $41.2 \%$ in electrical losses and $5 \%$ in overall operating costs can be obtained.

These are just some of the many works available in the scientific literature that address the problem of the optimal sizing of heat pumps coupled to buildings. It can be noted that they are mainly referred to evaluate the optimal configuration of the system for the specific case study. On the contrary, the analysis proposed in this work aims not to consider the impact of a specific building-heating system, but wants to provide a sensitivity analysis solely focused on the heat pump performance. Indeed, the purpose is to analyze, in an operating system, the mutual dependence of the design and control parameters of the HP on the overall energy performance. The evaluation aims to propose a mapping of the actual operation of a real heat pump with a view to provide guidelines for the design of a residential heating system with heat pumps.

With an energy simulation tool, a commercial variable-load air-to-water heat pump was modelled. It was used to cover the thermal demand of a reference residential building. The influence of different operating parameters was evaluated by simulating different scenarios and comparing the seasonal energy performance. In particular, the effect of the mutual influence of the rated heating capacity, the design supply side temperature and the control strategies (e.g. fixed supply temperature or climatic regulation) was analyzed. Furthermore, the effect of a thermal energy storage (i.e. a hot water tank) added to the HP water circuit was also evaluated.

The paper is organized as follows: in Section 2 the methodology is presented with the description of the HP modelling techniques and the scenarios investigated, Section 3 reports the details of the case study, Section 4 discusses the results of the analysis and in Section 5 the main conclusions of the study are summarized.

\section{METHODS}

In order to evaluate the impact of both the design and the control parameters of a real variable-load heat pump on the overall energy performance, different scenarios were simulated dynamically in TRNSYS [10]. The analysis presented in this work is focused on air-to-water heat pumps, as they represent one of the most widespread technologies in residential buildings [1].

Since in the standard TRNSYS libraries there are no models that allow to represent the behavior of an air-source variableload heat pump, its model was implemented with a TRNSYS calculator (details about the HP models are provided in Section 2.1).

The HP heat power was used to cover the thermal requirement of a reference building modelled in TRNSYS with Type 56. Details about the thermal and geometrical properties of the building are reported in the next section (Section 3), where the case study is presented. Different configurations for the design parameters of the HP and control strategies were tested. The description of the parameters that are varied in the different scenarios is discussed in Section 2.2.

The seasonal energy performance was evaluated under different scenarios. In particular, for each scenario the SCOP and the electricity consumption were calculated. Moreover, the impact of the parameters on the user's comfort was assessed by calculating the number of hours in which the thermostat was unable to maintain the temperature within the comfort temperature band.

\subsection{Variable load heat pump model}

As it is known, the performance of a variable-load heat pump is strongly dependent on the outdoor temperature, the water supply temperature and the modulation of the load. The latter quantity is commonly referred to as capacity ratio (CR) and represents the thermal power required by the heat pump in the specific operating conditions (i.e. outdoor and water supply temperatures) divided by the declared thermal power, referred to the same operating temperatures [3].

According to [5] and [3], three operating ranges can be distinguished based on the value assumed by the CR: (i) when the $\mathrm{CR}$ is equal to 1 , (ii) when the $\mathrm{CR}$ assumes values between 1 and a minimum modulation value $\mathrm{CR}_{\text {lim }}$ that depends on the features of the selected heat pump, and (iii) when CR is lower than $\mathrm{CR}_{\text {lim. }}$.

In case (i), the HP works at its full load conditions while in case (ii) the HP modulates the load. On the contrary, in case (iii) the HP works in on/off mode with a degradation of the performance.

The model of the HP differs according to the operating condition in which it operates. In particular, in this work the approach suggested by the Italian standard UNI TS 11300-4 [3] was adopted. Indeed, UNI TS 11300-4 suggests calculating the $\mathrm{COP}$ at partial load $\left(\mathrm{COP}_{\mathrm{pl}}\right)$ as the product between the $\mathrm{COP}$ at full load $\left(\mathrm{COP}_{\mathrm{fl}}\right)$ and a corrective factor $\left(\mathrm{f}_{\text {corr }}\right)$ that depends on the capacity ratio $(\mathrm{CR})$ :

$$
\mathrm{COP}_{\mathrm{pl}}=\mathrm{f}_{\mathrm{corr}} \cdot \mathrm{COP}_{\mathrm{fl}}
$$

To calculate the corrective factor $\left(\mathrm{f}_{\text {corr }}\right)$, manufacture data about COP measurements at different operating points (outdoor temperature, water supply temperature and CR) are required. Different operating ranges can be modeled as follows: 
- when CR is equal to $1, \mathrm{f}_{\text {corr }}$ is equal to 1 and to obtain the COP in conditions different from those in which the measurements (outdoor and water supply temperature) are available, the data declared by the manufacturer can be interpolated;

- when $\mathrm{CR}$ is between $\mathrm{CR}_{\lim }$ and $1, f_{\text {corr }}$, in conditions different from those in which the measurements are available, is calculated interpolating the data provided by the manufacturer;

- when $\mathrm{CR}$ is lower than $\mathrm{CR}_{\text {lim }}, f_{\text {corr }}$ is calculated according to Eq. (2), where $\mathrm{C}_{\mathrm{c}}$ is a degradation coefficient that in absence of data supplied by the manufacturer can be assumed equal to 0.9 [3]

$$
\mathrm{f}_{\text {corr }}=\frac{\mathrm{CR}}{\mathrm{C}_{\mathrm{c}} \mathrm{CR}+\left(1-\mathrm{C}_{\mathrm{c}}\right)}
$$

In Section 3, where the case study is presented, the modelling methodology is proposed with reference to manufacturer data for a commercial air-source variable-load heat pump.

In particular, it is important to highlight that, in order to evaluate the impact of different design parameters of the heat pump (e.g. size), the performance of a real HP was modelled by normalizing it according to the heat capacity data reported by the manufacturer. In this way, the same performance curves were used for different HP sizes and it was therefore possible to evaluate variations in the operating points (i.e. CR) in the different scenarios referring to the same performance map. Thus, the dependence on the specific model of heat pump wis avoided.

\subsection{Operating parameters}

In order to evaluate the impact of the design and control parameters on the actual operating conditions of the HP, different scenarios were simulated. In particular, the following parameters were varied.

- The size of the heat pump. The configurations tested referred to a thermal capacity equal to $125 \%, 100 \%, 80 \%$ and $60 \%$ of the design peak load of the building.

- The heating system configuration. Both the configurations with and without a thermal energy storage were tested. As concerns the TES model, a stratified hot water tank (Type 4) was selected. Also, different sizes of the tank were evaluated.

- The heat pump control strategy. The tested strategies are: (i) fixed supply temperatures (values of $45^{\circ} \mathrm{C}, 50^{\circ} \mathrm{C}$ and $55^{\circ} \mathrm{C}$ ) and (ii) supply temperature regulated with a compensation curve (i.e. climatic regulation). For the cases in which the heat pump was equipped with the TES, the compensation curve was applied in two different configurations: to select the HP water supply temperature or to control the supply temperature to the building (in this case, the HP was regulated with a fixed supply temperature). More details about the control strategies are provided in the next section where the case study is described.

\section{CASE STUDY}

To simulate the thermal demand of a reference building, a relatively recent single-family building (construction period after 2006) was modeled in TRNSYS. The thermal and geometric characteristics of the building were extrapolated by Tabula project [11] and they are reported in Table 1.

Table 1. Thermal and geometrical features of the building

\begin{tabular}{ccccc}
\hline & External Walls & Roof & Floor & Windows \\
\hline $\begin{array}{c}\text { U-value } \\
\left(\mathrm{Wm}^{-2} \mathrm{~K}^{-1}\right)\end{array}$ & 0.34 & 0.28 & 0.33 & 2.20 \\
\hline Surface $\left(\mathrm{m}^{2}\right)$ & 223.3 & 96.4 & 96.4 & 24.1 \\
\hline
\end{tabular}

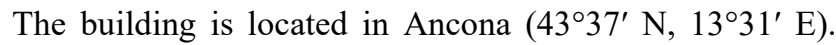
According to UNI 10349-2:2016 [12], the external design air temperature is $-2^{\circ} \mathrm{C}$. Therefore, for an indoor comfort temperature of $20^{\circ} \mathrm{C}$ [13], the calculated peak load of the building is about $3.5 \mathrm{~kW}_{\text {th }}(100 \%$ design size for the HP).

Applying the same approach used for the calculation of the peak load (i.e. stationary calculation) to different outdoor temperatures, the compensation curve of the heat pump was formulated (Figure 1). In particular, a fixed water flowrate of $0.12 \mathrm{~kg} \mathrm{~s}^{-1}$ was imposed. It was selected to provide the peak power with a temperature difference of $7^{\circ} \mathrm{C}$ at $-2^{\circ} \mathrm{C}$ (the minimum water return temperature was set to $38^{\circ} \mathrm{C}$ ).

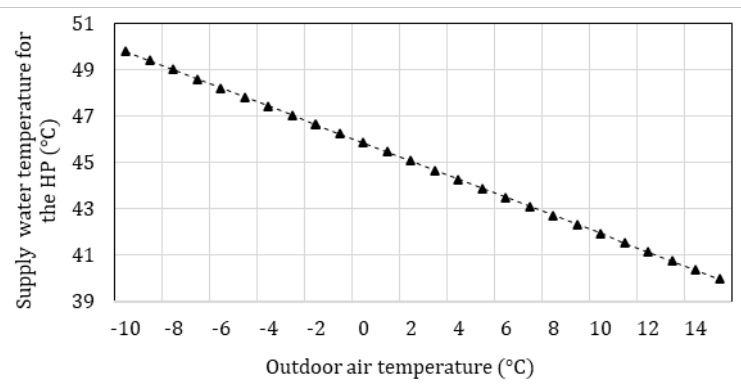

Figure 1. Compensation curve

To obtain the performance of the HP according to the method presented in the previous section, a commercial airsource variable-load heat pump was selected (Viessmann Vitocal 200-S [14]). This model has a rated heating capacity of $4.2 \mathrm{~kW}_{\text {th }}$, with a nominal COP of 4.55 (performance evaluated with an air temperature of $7^{\circ} \mathrm{C}$ and a water supply temperature of $\left.35^{\circ} \mathrm{C}, \mathrm{A} 7 \mathrm{~W} 35\right)$. However, as mentioned in Section 2.1, only the manufacture data related to the COP were used since the HP thermal capability was normalized as a function of the nominal data.

Figure 2 shows the corrective factor calculated as function of the capacity ratio for an external temperature of $-2^{\circ} \mathrm{C}$ and a supply water temperature of $45^{\circ} \mathrm{C}$. As can be noted, for the selected heat pump the minimum allowed modulation rate is about $0.42\left(\mathrm{CR}_{\lim }\right)$.

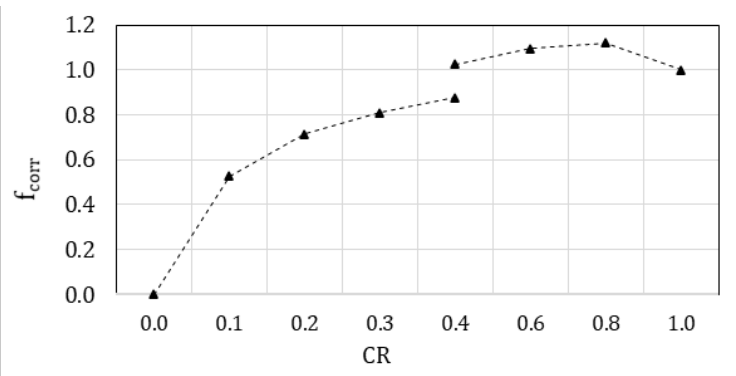

Figure 2. Corrective factor calculated for the selected heat pump (A45W-2) 
Radiators were used as thermal distribution system and they were modelled in TRNSYS with Type 1231.

A simple thermostat, modelled with Type 1502, was used to control the indoor air temperature of the building. In particular, the thermostat works to maintain the air temperature in the comfort band $20^{\circ} \mathrm{C} \pm 0.5^{\circ} \mathrm{C}$.

Figure 3 reports a schematic of the system modelled. As can be noted, this first configuration does not include the TES. The scenarios that this configuration allows to model are those with a fixed water supply temperature and with a compensation curve.

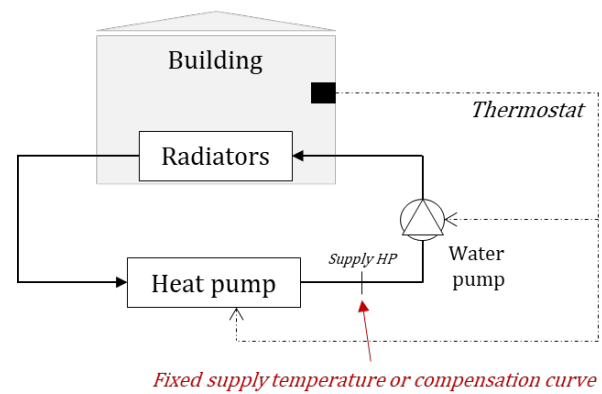

Figure 3. Schematic of the modelled heating system in the configuration without the TES

As mentioned, it was also considered the possibility of including a hot water tank in the heating system. As shown in Figure 4, two configurations of the heating system were modeled to implement two different control strategies of the system. In the first one (Figure 4(a)), the compensation curve is adopted to control the HP water supply temperature. On the contrary, Figure 4(b) shows a configuration in which the compensation curve sets the supply water temperature to the radiators (Section 2.2) and the heat pump is regulated with a fixed water supply temperature of $50^{\circ} \mathrm{C}$. In this latter case, a bypass on the return water temperature is necessary.

In both the cases, the high temperature of the tank was controlled (tank control in Figure 4) with a simple controller (Type 2) that maintains it in the range $50 \pm 5^{\circ} \mathrm{C}$.

The effect of different tank sizes was investigated: 200 liters, 400 liters, 600 liters, 800 liters and 1000 liters TES were tested. The values were selected with reference to commercial hot water tanks [15].

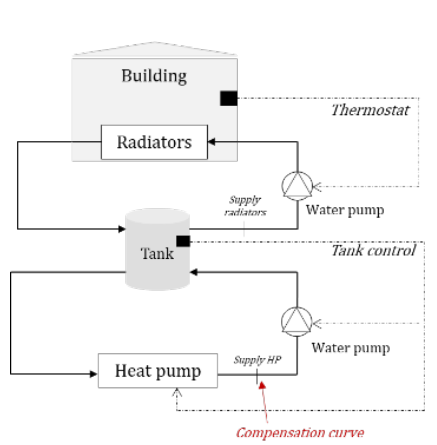

(a)

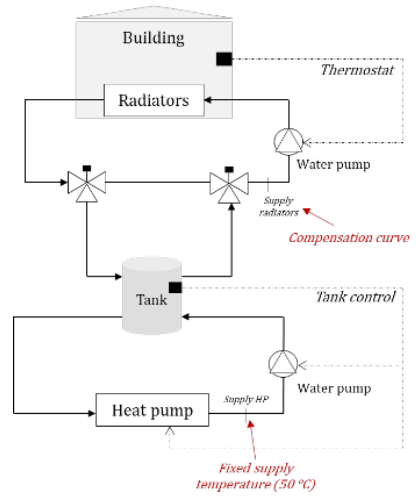

(b)
Figure 4. Schematic of the modelled heating system in the configuration with the TES: (a) no compensation curve for the radiators water supply temperature and (b) compensation curve for the radiators water supply temperature

\section{RESULTS}

To evaluate the scenarios identified in Section 2.2, energy simulations referred to the whole heating season (from November 1st to the 15th of April for Ancona) were carried out. The first scenario deals with the configurations without the TES (Figure 3). The configurations investigated were two: fixed values of heat pump water supply temperatures $\left(45^{\circ} \mathrm{C}\right.$, $50^{\circ} \mathrm{C}$ and $55^{\circ} \mathrm{C}$ ) and a climatic regulation with a compensation curve (Figure 1)

Figure 5 represents the values of the SCOP obtained in these scenarios, when the design size of the heat pump is also varied. Considering only the configuration with fixed supply temperatures, as expected, the best performance is obtained with the lowest value of the supply temperature $\left(45^{\circ} \mathrm{C}\right)$. However, it can be noted that, for all the three observed supply temperatures, slightly higher SCOP values were obtained for the larger sizes of the heat pump $(125 \%$ and $100 \%$ of the design size). This is due to the fact that, as the size varies, the operating points (i.e. CR) of the heat pump change.

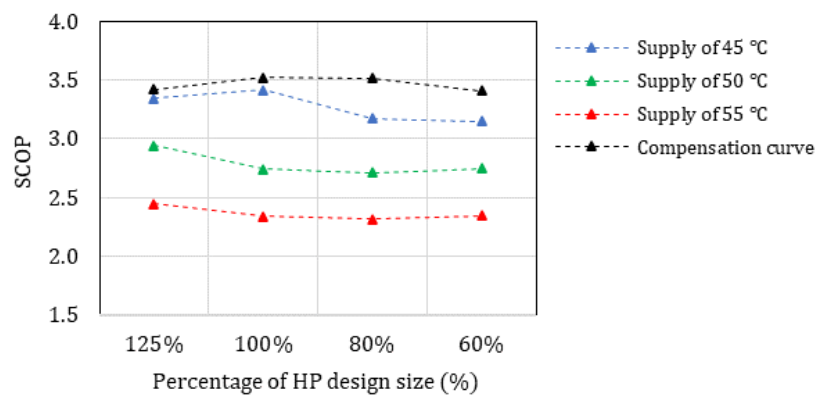

Figure 5. SCOP for scenarios with different regulation of the water supply temperatures and design sizes of the HP (configuration without TES)

Figure 6 represents the number of the HP working hours in the different simulated scenarios, distinguishing the time intervals in which the heat pump has operated in different ranges of CR. Looking at the scenarios evaluated with a supply temperature of $45^{\circ} \mathrm{C}$ in Figure 6(a), it can be clearly observed that, as the size of the heat pump increases, the number of hours the HP is running at CR lower than 1 increases (in particular, in the range between 0.6 and 0.9). Since in this case the value of $f_{\text {corr }}$ is greater than 1 (Figure 2), this translates into an improvement of the seasonal performance.

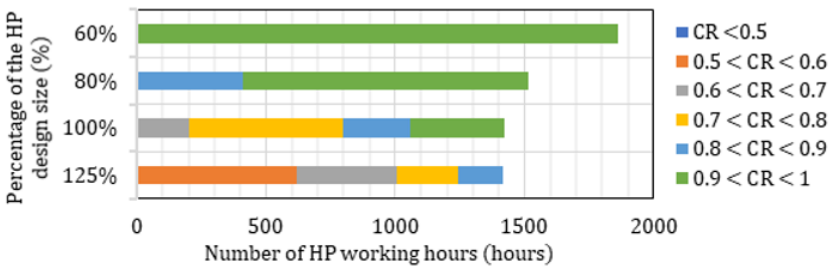

(a)

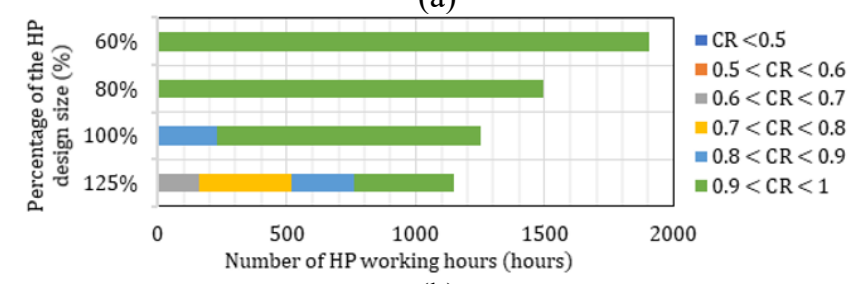

(b) 


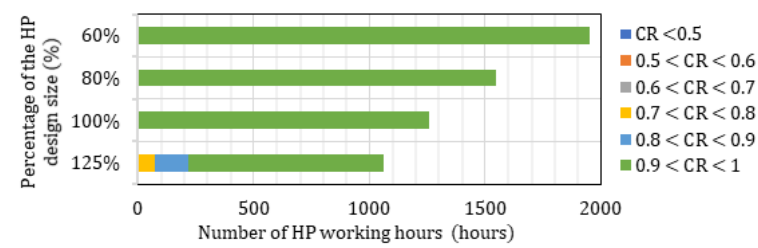

(c)

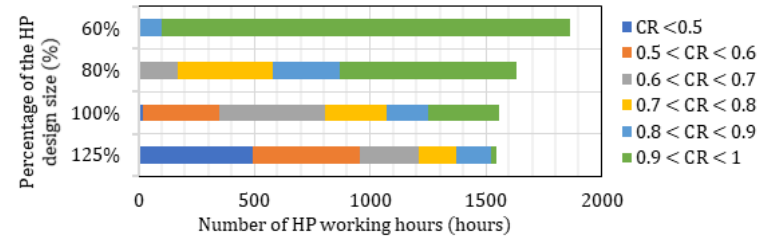

(d)

Figure 6. Number of working hours of the heat pump (configuration without TES): (a) fixed supply temperature at $45^{\circ} \mathrm{C}$; (b) fixed supply temperature at $50^{\circ} \mathrm{C}$; (c) fixed supply temperature at $55^{\circ} \mathrm{C}$ and $(\mathrm{d})$ compensation curve

Furthermore, smaller heat pumps $(60 \%$ and $80 \%$ of the design size) do not always allow to keep the indoor air temperature within the range set by the thermostat. To confirm that, Figure 7 represents the percentage of time in which the indoor air setpoint is not maintained (i.e. the air temperature falls below $19.5^{\circ} \mathrm{C}$ ).

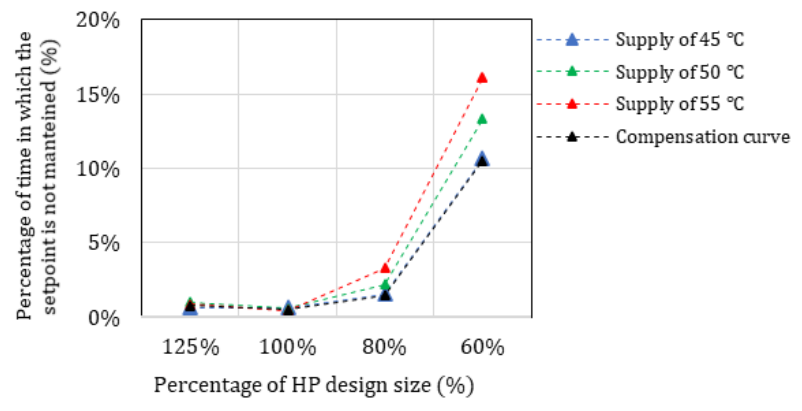

Figure 7. Percentage of time in which the indoor air setpoint is not maintained for scenarios with different regulation of the water supply temperatures and design sizes of the HP (configuration without TES)

As can be noted by looking at Figures 5, 6 and 7, it seems that the introduction of the compensation curve (Figure 1) allows to obtain the best performance in terms of SCOP. Moreover, the results depicted in Figures 5 and 6 show that in presence of the compensation curve, a larger size of the heat pump (125\% of the design size) does not allow to obtain the performance improvement observed for the cases at constant supply temperature. This is due to the fact that, in this latter configuration, the HP operates for a longer time at low CR values (even below 0.5, as shown in Figure 6(d)). The behavior is also confirmed by the results provided in Table 2, where the seasonal values of the average $\mathrm{CR}$ were calculated for the scenarios without the TES.

Moving on to analyze the cases involving the TES, as mentioned in Section 2.2 two different configurations were investigated for different sizes of the tank. Referring to the compensation curve applied to the supply temperature of the HP (Figure 4(a)), Figure 8 shows the seasonal performance of the HP as the size of the tank varies. Differently from what observed for the previous cases (Figure 5), the SCOP of the heat pump improves as the percentage of the HP design size decreases for each size of the tank. This depends on the working conditions of the heat pump in such schematic.

Table 2. Values the seasonal average CR for scenarios with different regulation of the water supply temperatures and design sizes of the HP (configuration without TES)

\begin{tabular}{ccccc}
\hline \multirow{2}{*}{ Regulation of the HP supply } & \multicolumn{4}{c}{ Percentage of HP design size } \\
\cline { 2 - 5 } & $125 \%$ & $100 \%$ & $80 \%$ & $60 \%$ \\
\hline Compensation curve & 0.59 & 0.73 & 0.87 & 0.99 \\
\hline Fixed at $45{ }^{\circ} \mathrm{C}$ & 0.65 & 0.81 & 0.95 & 1.00 \\
\hline Fixed at $50{ }^{\circ} \mathrm{C}$ & 0.84 & 0.96 & 1.00 & 1.00 \\
\hline Fixed at $55^{\circ} \mathrm{C}$ & 0.96 & 1.00 & 1.00 & 1.00 \\
\hline
\end{tabular}

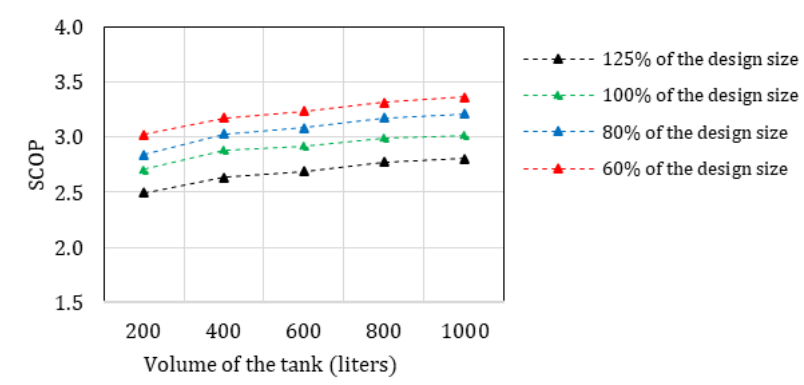

Figure 8. SCOP for scenarios with different size of the tank (compensation curve to set the supply temperature of the HP)

Looking at Table 3, an explanation of the behavior observed in Figure 8 can be deducted. Indeed, for $60 \%$ of the HP design size, average values of CR close to 0.75 , which correspond to higher values of $f_{\text {corr }}$ (Figure 2), were obtained. For the highest sizes of the HP, the average CR decreases, bringing the heat pump to work for a longer time at points where the performance is degraded. However, taking as reference an intermediate volume (e.g. 600 liters) for the TES, the heat pump operates for a longer time at lower CR than those in the configuration without the TES (Figure 9 in comparison with Figure 6(d)). This is also the reason why the SCOP values are generally lower in the case with the TES than in the case without it.

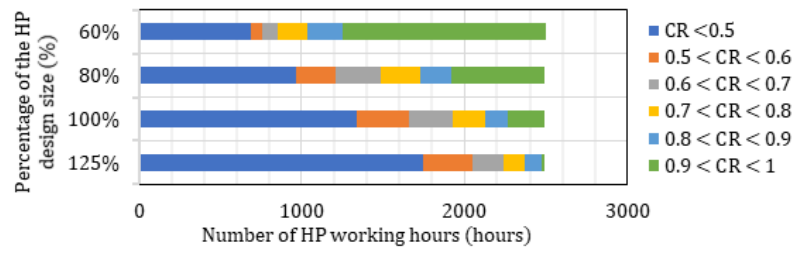

Figure 9. Number of working hours of the heat pump for scenarios with a tank of 600 liters (compensation curve to set the supply temperature of the HP)

Table 3. Values of the seasonal average CR for scenarios with different sizes of the tank (compensation curve to set the supply temperature of the HP)

\begin{tabular}{ccccc}
\hline \multirow{2}{*}{ Size of the tank } & \multicolumn{4}{c}{ Percentage of HP design size } \\
\cline { 2 - 5 } & $125 \%$ & $100 \%$ & $80 \%$ & $60 \%$ \\
\hline 200 liters & 0.36 & 0.45 & 0.56 & 0.70 \\
\hline 400 liters & 0.37 & 0.46 & 0.57 & 0.72 \\
\hline 600 liters & 0.38 & 0.47 & 0.58 & 0.74 \\
\hline 800 liters & 0.38 & 0.48 & 0.59 & 0.75 \\
\hline 1000 liters & 0.38 & 0.48 & 0.59 & 0.75 \\
\hline
\end{tabular}


In any case, by looking at the results provided in Figure 8, an increase in the seasonal performance of the HP can also be noted when the size of the tank increases. This behavior can be observed for each size of the heat pump.

Analyzing the results obtained for the other control strategy in the configuration with the TES (compensation curve applied to the radiator supply temperature and HP regulated with a constant temperature of $50^{\circ} \mathrm{C}$, Figure $4(\mathrm{~b})$ ), Figure 10 shows the seasonal performance of the HP in different sizes of the tank. Even in this case, the seasonal performance improves as the size of the heat pump decreases; however, a general decrease in the SCOP values compared to the case studied in Figure 8 is observed. This is due to the fact that, in this configuration, the hours of operation at low CR increase even more for each size of the heat pump (Figure 11). The increasing trend of the SCOP with the size of the tank is also confirmed for each HP size.

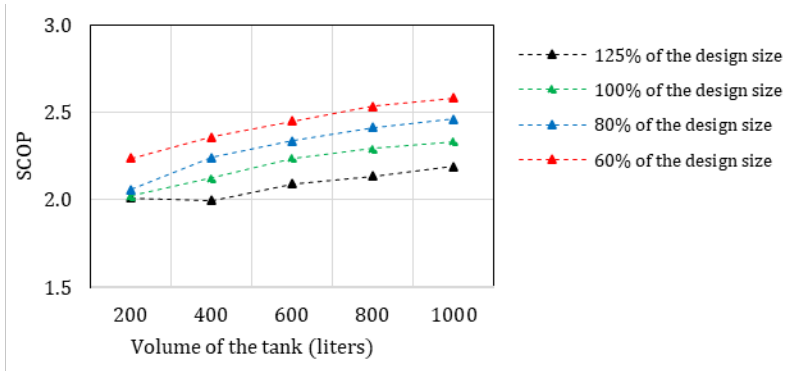

Figure 10. SCOP for scenarios with different size of the tank (compensation curve to set the supply temperature of the radiators and fixed temperature for the HP supply)

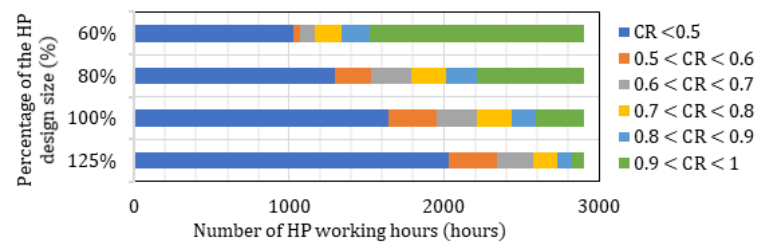

Figure 11. Number of working hours of the heat pump for scenarios with tank of 600 liters (compensation curve to set the supply temperature of the radiators and fixed temperature for the HP supply)

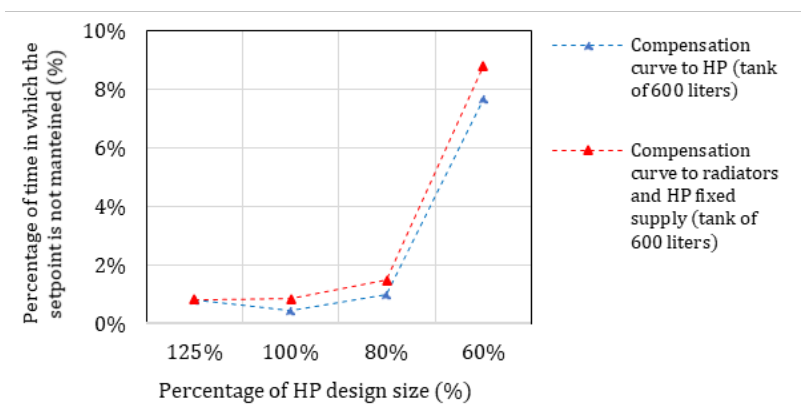

Figure 12. Percentage of time in which the indoor air setpoint is not maintained for scenarios with TES (600 liters)

Always taking an intermediate tank size (600 liters) as a reference (for the other sizes, the same behavior occurs), as for the scenarios reported in Figure 7, it can be noted that the size of the HP influences the number of hours in which the comfort set-point temperature cannot be maintained (Figure 12). However, in both configurations with the TES, a behavior similar to the case of the regulation with compensation curve without the tank (Figure 7) can be observed.

In general, albeit considering a simple case, the results show a strong dependence of the operative performance of a variable-load heat pump on the design and operating parameters of the system. Difference in the configuration with and without the TES can be noted especially in relationship to the size of the heat pump chosen. Indeed, for the configurations without the TES, the results show that with large sizes of the heat pump and as the supply temperature decreases, there is an improvement in seasonal performance. It is interesting to notice that, a further increase is observed if the regulation is climatic. On the other hand, the addition of a TES forces the heat pump to work at lower CR for a longer time showing results that suggest the adoption of smaller sizes of the heat pump.

\section{CONCLUSIONS}

The aim of this work was to analyze, in an operating system, the mutual dependence of the design and control parameters of a variable-load air-source heat pump applied to a residential building.

Through dynamic energy simulations, different scenarios were evaluated for the whole heating season. Two configurations of the heating system were modelled, one with and one without a thermal energy storage (a hot water tank of variable size). The parameters that were varied to identify different scenarios were: rated heat pump heating capacity, design supply side temperature and control strategies (e.g., fixed supply temperature or climatic regulation).

Since the performance of a variable-load heat pump is very dependent on its modulation (capacity ratio), different behaviors can be observed in the various scenarios in relation to the points in which the heat pump most frequently works.

The obtained results allow to confirm the dependance of the design parameters and the control strategy on the actual performance of a variable-load heat pump. Indeed, considering scenarios without the addition of thermal energy storage, results show the improvement of the seasonal energy performance with larger sizes of the heat pump (i.e. between $100 \%$ and $125 \%$ of the building design peak load) and low values of the water supply temperature. On the other hand, if a hot water tank is added to the HP circuit, the seasonal energy performance increases as the size of the heat pump decreases. Furthermore, in both the configurations (with and without the thermal energy storage), the climatic regulation allows to minimize the number of hours in which the thermostat is not able to maintain the imposed comfort conditions.

It is interesting to notice that, although limited by the simplicity of the case study examined, the analysis allowed the identification of the first general indications to suggest the sizing of different configurations of residential heating systems equipped with a variable-load heat pump. However, it would be interesting to extend the proposed analysis to other case studies that also include different types of heat pumps and distribution systems (i.e. radiant heating systems) or to repeat the study in the case of cooling.

\section{REFERENCES}

[1] I.E.A. (2021). Heat Pumps. 
[2] Fischer, D., Madani, H. (2017). On heat pumps in smart grids: A review. Renewable and Sustainable Energy Reviews, 70 : $342-357$ https://doi.org/10.1016/j.rser.2016.11.182

[3] UNI/TS. (2016). UNI TS/11300-4. Energy performance of buildings - Part 4: Use of renewable energy and other generation methods for winter air conditioning and for the production of domestic hot water.

[4] EN. (2018). EN 14825. Air conditioners, liquid chilling packages and heat pumps, with electrically driven compressors, for space heating and cooling - Testing and rating at part load conditions and calculation of seasonal performance.

[5] Bee, E., Prada, A., Baggio, P. (2016). Variable-speed airto-water heat pumps for residential buildings: evaluation of the performance in northern Italian climate. In Proceedings of the 12th Rehva World Congress (CLIMA 2016), Aalborg, Denmark, pp. 22-25.

[6] Dongellini, M., Naldi, C., Morini, G.L. (2021). Influence of sizing strategy and control rules on the energy saving potential of heat pump hybrid systems in a residential building. Energy Conversion and Management, 235: 114022.

https://doi.org/10.1016/j.enconman.2021.114022
[7] Lin, Y., Wang, H., Hu, P., Yang, W., Hu, Q., Zhu, N., Lei, F. (2020). A study on the optimal air, load and source side temperature combination for a variable air and water volume ground source heat pump system. Applied Thermal Engineering, 178: 115595. https://doi.org/10.1016/j.applthermaleng.2020.115595

[8] Blackman, C., Gluesenkamp, K.R., Malhotra, M., Yang, Z. (2019). Study of optimal sizing for residential sorption heat pump system. Applied Thermal Engineering, 150: 421-432. https://doi.org/10.1016/j.applthermaleng.2018.12.151

[9] I CARICHI TERMICI.

[10] T. energy system Specialists, TRNSYS Software.

[11] Corrado, V., Ballarini, I., Corgnati, S.P. (2012). Typology Approach for Building Stock: D6. 2 National Scientific Report on the TABULA activities in Italy.

[12] UNI/TR. (2016). 10349-2. Heating and cooling of buildings - Climatic data - Part 2: Data for design load.

[13] UNI/TS 11300-1. (2014). Energy performance of buildings Part 1: Evaluation of energy need for space heating and coolin.

[14] Viessmann. VITOCAL 200-S, Commer. Cat.

[15] Kloben, Catalogue for thermal storage. 